\title{
Notice of Grant Award
}

National Cancer Institute

\section{Source}

National Cancer Institute. Notice of Grant Award. NCI Thesaurus. Code C60764.

A document providing formal acknowledgement of a grant application's approval for funding. 